\title{
"EL PERÚ SOY YO": NÓBEL DE LITERATURA
}

\author{
"I AM PERU": LITERATURE NOBEL \\ Martín Nizama Valladolid ${ }^{1}$ \\ Clínica Nizama, Lima, Perú \\ (ReCiBido el 12/11/2010, ACEPTADo el 9/12/2010)
}

\begin{abstract}
RESUMEN
Se revisa la ruta de vida del insigne escritor, político, libre pensador, demócrata y humanista, se analizan elementos más que suficientes que lo catalogan como un peruano universal, un ser humano pletórico de generosidad. Se hace una remembranza de los momentos inolvidables desde el anuncio de la concesión del premio, en el Instituto Cervantes de Nueva York; luego el momento en que el rey Carlos XVI Gustavo de Suecia entregó, el Premio Nóbel de Literatura 2010 a Mario Vargas Llosa (MVLl) en la Sala de Conciertos de Estocolmo. MVLl en su discurso de agradecimiento en Nueva York, manifestó ante la prensa internacional que el premio era un galardón al idioma español e hizo gala de lo mejor de su erudición en un discurso lleno de emociones y expresó su peruanidad a todo el mundo con un enunciado que quedará perennizado: "EL PERÚ SOY YO". Expresiones de grandeza y agradecimiento a su país, en las que el flamante Premio Nóbel de 74 años sintetizó su profunda peruanidad, y con las cuales llenó de orgullo a los aproximadamente 30 millones de peruanos, sedientos de trascendentales triunfos. Se analiza su origen arequipeño, su entorno familiar, su infancia, niñez y adolescencia en Cochabamba, Piura y Lima; la relación conflictiva con su padre, su adolescencia en el Colegio Militar Leoncio Prado, donde se inició su vocación literaria; dichas experiencias evocadas en su libro autobiográfico "El Pez en el Agua"; luego sus raíces telúricas, su paso por la Universidad Nacional Mayor de San Marcos, donde comenzó a publicar sus primeros relatos. Asimismo, se aborda su consagrada vida a favor de la lucha por la libertad, los derechos civiles y los derechos humanos y su incursión en la política peruana. Finalmente, un colofón describiendo al MVLl humano, su profunda sensibilidad, expresión de amor a la libertad, su capacidad creativa inagotable, su pensamiento ideológico, y su perseverancia, para darnos cuenta que estamos frente a un humanista ecuménico.
\end{abstract}

Palabras clave: Premio Nóbel, Mario Vargas Llosa, literatura.

\begin{abstract}
The route of life of insigne is reviewed writer, politician, free thinker, democrat and humanist, analyze elements than sufficient more they catalogue that it like Peruvian a universal one, a human being full of generosity. One becomes remember of the unforgettable moments from the announcement of the concession of the prize, in the Cervantes Institute of New York; soon the moment at which king Carlos XVI Gustavo of Sweden gave, the Nobel prize of Literature 2010 to Mario Vargas Llosa (MVLl) in the Concert hall of Stockholm. MVLl in its speech of gratefulness in New York, showed before the international press that the prize
\end{abstract}

1 Médico Psiquiatra. Director de la Clínica Nizama, especializada en Adicciones, de Lima, Perú. E-mail: maniva@terra.com.pe 
was an award to the Spanish language and displayed the best thing of its erudition in a full speech of emotions and expressed its peruanity to everybody with a statement that will be unforgettable: "PERU I AM". Expressions from greatness and gratefulness to their country, in which the flaming Nobel prize of 74 years synthesized its deep peruanity, and with which it filled of pride approximately to 30 million of Peruvian, thirsty of transcendental triumphs. Its origin arequipeño, its familiar surroundings, its childhood, childhood and adolescence in Cochabamba, Piura and Lima are analyzed; the conflicting relation with its father, its adolescence in the Military School Leoncio Prado, where its literary vocation began; these experiences evoked in its autobiographical book "the Fish in the Water"; soon its telluric roots, its passage by the Greater National University of San Marcos, where it began to publish his first stories. Also, his consecrated life in favour of the fight by the civil freedom, rights and the human rights and their incursion in the peruvian politic is approached. Finally, a finishing touch describing to the human MVLl, its deep sensitivity, expression of love to the freedom, its inexhaustible creative capacity, its ideological thought, and its certainly, to give account us that we are in front of an ecumenical humanist.

Keywords: Nobel prize, Mario Vargas Llosa, literature.

\section{CONTEXTUALIZACIÓN}

El Perú se sintió feliz el 10 de diciembre de 2010, cuando el rey Carlos XVI Gustavo de Suecia le entregó, por fin, el Premio Nóbel de Literatura 2010 a Mario Vargas Llosa en la Sala de Conciertos de Estocolmo. Dos meses antes, el 07 de octubre, día en que la Academia Sueca le anunció la concesión del soñado premio, en el Instituto Cervantes de Nueva York, Mario Vargas Llosa (MVLl) manifestó exultante ante la prensa internacional que consideraba que el premio era un galardón al idioma español y respecto a su producción literaria manifestó: "lo que hago, lo que digo, expresa el país en el que he nacido, el país en el que he vivido las experiencias fundamentales que marcan a un ser humano, que son las de infancia y juventud, de tal manera que el Perú soy yo. Yo le puedo agradecer a mi país lo que soy, el ser un escritor". Expresiones de grandeza en las que el flamante Premio Nóbel de 74 años sintetizó su peruanidad profunda, y con las cuales llenó de orgullo a los aproximadamente 30 millones de peruanos, sedientos de triunfos trascendentales y de paradigmas íntegros.

En este sentido, su vasta creación literaria trasunta que de juegos de poder, miedo, disimulo, violencia y venganza suelen desbordarse las relaciones sociales en países bajo regímenes castrenses. Concepción que el flamante Nóbel sintetizó en una caricatura pertinente: "Y el Leoncio Prado era un Perú chiquito" (El Comercio, 09 de enero del 2011).

Al revisar la ruta de vida del insigne escritor, político, libre pensador, demócrata y humanista, hay elementos más que suficientes que lo catalogan como un peruano universal. Examinemos a continuación a este ser humano pletórico de generosidad, tal como lo definió Fernando Savater (El Comercio, 17 de octubre del 2010).

\section{Origen}

MVLl nació el 28 de marzo de 1936, en la bella ciudad Blanca, Arequipa. Hijo único de Ernesto Vargas Maldonado y de Dora Llosa Ureta, quienes habían contraído matrimonio 
el 04 de junio del año anterior; ceremonia que tuvo lugar en casa de sus abuelos maternos, ubicada en el segundo piso del bulevar Parra de la ciudad mistiana. Tras la boda, de inmediato, la pareja viajó a Lima, radicándose en Miraflores.

\section{Entorno familiar}

Al nacer, en niño Mario se convirtió en el primer nieto, el primer sobrino y "el hijo de la pobre Dorita, un niño sin papá", que en compensación tenía varios padres putativos, todos ellos cual más complacientes, permisivos y tolerantes: su abuelo Pedro y sus tíos Juan, Lucho, Jorge y Pedro. En la infancia, el niño fue el centro de atención de la extensa familia Llosa, de quienes "fui engreído y consentido hasta unos extremos que hicieron de mí un pequeño monstruo", capaz de hacer "diabluras". Así, cuando el niño se negaba a comer, el abuelo Pedro dulcemente le decía "para el poeta la comida es prosa", sembrándole con la mayor naturalidad la semilla de la inspiración y la ficción.

Su padre, Ernesto Vargas, era persona autoritaria, posesiva, de "mal carácter", con "celos endemoniados" y violento, afectado por "el resentimiento y los complejos sociales", "enfermedad nacional por antonomasia... que infesta todos los estratos y familias del país y en todos deja un relente que envenena la vida de los peruanos", debido a la mejor posición social de la familia materna, que pertenecía a la burguesía arequipeña, muy bien relacionada, situación que él no poseía y que al parecer no toleraba; puesto que el señor Vargas pertenecía "a una familia socialmente inferior a la de su mujer". Por ello, a decir del escritor, tras el matrimonio, "lo que le deparó fue un desastre" a su madre, quien "fue sometida a un régimen carcelario" y tiránico: "Las escenas de celos se sucedían por cualquier pretexto y a veces sin pretexto y podían degenerar en violencias". La señora Dora quedó embarazada al poco tiempo de casarse y los primeros meses de gestación los pasó sola en Lima. Mas, una mañana de noviembre de 1935, a los 5 meses de embarazo "ese ser desenraizado, sin familia y sin pasado que era mi padre", dijo a su mujer: "Anda tú a tener el bebé a Arequipa, más bien". Se despidió cariñosamente de ella y viajó a La Paz, Bolivia donde laboró tres meses, y regresó a Lima sin informar nada a su mujer. Entonces, ella retornó a casa de sus padres en Arequipa, donde fue acogida con la calidez de una familia tradicional, cuyo patriarca era el abuelo Pedro Llosa Bustamante. El matrimonio había durado apenas dos meses y medio. Por este desenlace abrupto, la señora Dora tuvo que soportar con estoicismo las habladurías que con maledicencia inventaba la gente de su entorno social. Mientras que su esposo desapareció durante 11 años sin dar ninguna señal de existencia. Incluso ante una discreta indagación solicitada por la familia Llosa por intermedio de un familiar en Lima a Ernesto Vargas sobre el futuro de su relación matrimonial, por exigencia de él, la pareja se divorció "por mutuo disenso, a través de abogados, sin que los e.cónyuges tuvieran que verse las caras", según testimonio del escritor en su libro autobiográfico (1).

Para paliar la afrenta familiar por tan misterioso abandono, la familia Llosa tuvo que darlo por muerto, engañando al niño Mario que su papito se encontraba en el cielo. Desde entonces, le pusieron en el velador la foto de su padre, un apuesto joven, alto, vestido de marino, que el niño besaba y ante la cual rezaba antes de dormir, hasta que una tarde de 1946 en el malecón Eguiguren del río Piura, su madre sorpresivamente le reveló que su 
padre vivía, que no había muerto, que se encontraba en la ciudad y sin que los abuelos sepan, secretamente, lo estaba conduciendo al Hotel de Turistas donde él vio por primera vez a su padre. Al visualizarlo, se sintió estafado: "este papá no se parecía al que yo creía muerto" y el escritor se refiere a él despectivamente como "ese señor que era mi papá" (1). El mismo día del primer encuentro en el Hotel de Turistas de Piura, con engaños y la complicidad de su madre, los tres viajaron a Lima, en el automóvil Ford azul de su padre, sin que sus abuelos Pedro y Carmen ni sus tíos maternos lo supieran. Durante el sorpresivo viaje hicieron escala en el km 50, Chiclayo y Chimbote, antes de llegar a la capital. En el camino, el niño Mario sentía rabia y celos. Rápidamente se dio cuenta que sus padres se habían reconciliado y tenía celos al sentir que su padre le había arrebatado a su madre. Al llegar a Lima, la familia Vargas Llosa radicó en Magdalena del Mar y matriculó a Mario en el colegio La Salle, donde cursó el sexto año de primaria, primero y segundo de secundaria (1947-1949). En La Salle, creyendo que una falsificación de notas pasaría desapercibida, cambió en su libreta de notas la letra D de "deficiente" que le había puesto un profesor maleficente por la $\mathrm{O}$ de "óptimo". Una vez descubierto el fraude, el director del colegio, hermano Agustín citó al padre, quien tras el recreo se acercó a la formación de los escolares y "me lanzó un bofetón que electrizó a las decenas de muchachos. Luego, cogiéndome de una oreja, me arrastró hasta la dirección, donde volvió a pegarme, ante el hermano Agustín, quien trataba de apaciguarlo". En otra oportunidad anterior, su tío César, hermano de don Ernesto, acompañado de sus tres hijos, lo invitó al fútbol; sin embargo Mario se rehusó porque no tenía el permiso de su padre. Su tío lo persuadió diciéndole que él se lo explicaría a su hermano y se fueron. Al regresar, los esperaba don Ernesto en la calle, junto a la puerta de la casa de su tío César: "Todavía recuerdo el gran escándalo, los gritos al pobre tío César, que retrocedía, confuso, dándole explicaciones, y mi propio espanto, mientras mi padre me regresaba a la casa dándome de puntapiés. Cuando me pegaba, yo perdía totalmente los papeles, y el terror me hacía muchas veces humillarme ante él y pedirle perdón con las manos juntas. Pero ni eso lo calmaba. Y seguía golpeando, vociferando y amenazándome... Cuando aquello terminaba, y podía encerrarme en mi cuarto, no eran los golpes, sino la rabia y el asco conmigo mismo por haberle tenido tanto miedo y haberme humillado ante él de esa manera, lo que me mantenía desvelado, llorando en silencio". Ante semejantes episodios de violencia de su padre, MVLl, refiere: "Yo sentía pánico. Me temblaban las piernas. Quería volverme chiquito, desaparecer. Y, cuando, sobreexcitado con su propia rabia, se lanzaba a veces contra mi madre, a golpearla, yo quería morirme de verdad, porque incluso la muerte me parecía preferible al miedo que sentía" (1).

Así, desde que se conocieron en Piura la relación con su padre fue tormentosa e insoportable para Mario. El autoritarismo, la intolerancia, los arrebatos de celos, el resentimiento contra la familia Llosa y la repulsión hacia la vocación poética y literaria de su hijo, que don Ernesto Vargas valoraba despectivamente como extravagancia y "mariconería" moldeada por los "Llosa". Esta sostenida relación conflictiva infundió terror y odio en Mario contra su intransigente padre, quien en 1950 cuando Mario tenía 14 años lo matriculó en el Colegio Militar Leoncio Prado, donde cursó el tercero y cuarto de secundaria (1950-1951), supuestamente para acabar con la "mariconería" intelectual de su vástago. Ante la férrea disciplina militar a la cual no estaba acostumbrado, el adolescente Mario 
se refugió en la lectura y se dedicó a escribir poesías, cartas a las enamoradas de sus condiscípulos y folletos literarios. Fue entonces que comenzó a fraguarse en él la vocación de escritor, inspirado en sus paradigmas Alejandro Dumas y Víctor Hugo, cuyas obras maestras leía con fruición y embeleso.

En el verano de 1952, comenzó a laborar como ayudante en el diario La Crónica, luego pasó a aprendiz de periodista, siendo asignado como jefe de la sección policial, donde realizaba reportajes y entrevistas sazonadas con un breve período de bohemia que él refiere como "mis tres meses de periodista noctámbulo y prostibulario". A partir de entonces, con la aquiescencia de su padre decidió ser periodista, para lo cual debía laborar como tal y a la par cursar el quinto año de secundaria. Y, la única posibilidad de realizar ambas actividades en forma paralela, era estudiar en un colegio nacional. Sin embargo, debido a su bohemia y exceso de confianza, no encontró vacante en los colegios nacionales capitalinos. Entonces, de prisa, por teléfono pidió ayuda a su tío Lucho Llosa quien se había quedado a residir en Piura. Al conocer el trance, su tío Lucho de inmediato lo matriculó en el Colegio Nacional San Miguel. Fue así como se fue a residir a Piura a casa de sus queridos tíos Lucho y Olga, su esposa. Debido a estas circunstancias, fue que el e.estudiante leonciopradino acabó estudiando el quinto año de secundaria en el histórico colegio piurano, cumpliéndose su deseo de estudiar y ejercer el periodismo. En efecto, trabajó en el diario La Industria de esa ciudad, merced a sendas recomendaciones epistolares de dos periodistas amigos suyos, Alfonso Delboy y Gastón Aguirre Morales, dirigidas al propietario de dicho periódico, Miguel F. Cerro Guerrero. En La Industria MVLl trabajó el año 1952 como redactor de noticias, publicaba poemas de su autoría y escribía artículos de opinión.

En 1953, postuló e ingresó a la Universidad Nacional Mayor de San Marcos donde estudió Literatura y Derecho. Fue discípulo y asistente de Raúl Porras Barrenechea e integró en la Universidad el grupo comunista Cahuide. En 1958 optó el grado de Bachiller en Humanidades con la tesis: Bases para una Interpretación de Rubén Darío. Fue reconocido como el alumno más distinguido de literatura y viajó a España con una beca a realizar estudios de postgrado en la Universidad Complutense de Madrid, continuando su estela de escritor en París, Madrid, Barcelona y Londres, hasta convertirse en figura descollante de la narrativa latinoamericana y ganar merecidamente el Premio Nóbel de Literatura, siendo el primer peruano en lograrlo.

A los 19 años de edad (1955) se había casado con su tía política Julia Urquidi Illanes, 10 años mayor que él. Ante el rechazo familiar por esta decisión, tuvo que apartarse de su familia. Para su sostenimiento tuvo que ejercer siete trabajos simultáneos: librería, asistente de su maestro Raúl Porras Barrenechea, escribía para varios medios y catalogaba nombres de lápidas en el Cementerio Presbítero Maestro de Lima. En 1964 se divorció de Julia Urquidi. Después se casó con su prima Patricia Llosa, con quien tiene tres hijos: Álvaro, Gonzalo y Morgana.

\section{Raíces telúricas}

MVLl sólo vivió un año de su vida en su natal Arequipa. A esa edad, su abuelo Pedro fue contratado para administrar unos sembríos de algodón en Cochabamba, Bolivia, ciudad 
en la que fue designado Cónsul Honorario del Perú. Según cuenta MVLl, en el colegio La Salle de esa ciudad "aprendí a leer en la clase del hermano Justiniano" a los cinco años, y continuó sus estudios hasta el cuarto de primaria en 1945. Hasta ese año la familia radicó en Cochabamba. Entonces, cuando él tenía 9 años de edad, su abuelo Pedro fue designado Prefecto de Piura por el nuevo presidente José Luis Bustamante y Rivero (1946-1948). Por ese motivo, en 1946, toda la familia retornó al Perú y con parte de ella fue a residir a la cálida ciudad de Piura, donde Mario estudió el quinto año de primaria en el colegio Salesiano (1946), acabando cuando tenía 10 años de edad. Seguidamente, la familia se trasladó a residir a Lima donde estudió sexto año de primaria y los dos primeros años de secundaria en el colegio religioso, La Salle (1947-1949). Más, su padre preocupado por la inclinación del adolescente hacia la poesía y la literatura lo matriculó en el Colegio Militar Leoncio Prado, en el cual cursó tercero y cuarto de secundaria (1950-1951), para finalmente recalar nuevamente en Piura donde estudió el quinto año de secundaria en el Colegio Nacional San Miguel, en 1952, año que él rememora con excelsa gratitud. De su infancia, niñez y adolescencia en Cochabamba, Piura y Lima, MVLl evoca sus experiencias formativas básicas (1).

\section{Apología a su esposa}

En el discurso de aceptación del Premio Nóbel, en presencia de su esposa, Patricia Llosa Urquidi, MVLl, quebrándose emocionalmente leyó: "El Perú es Patricia, la prima de naricita respingada y de carácter indomable con la que tuve la fortuna de casarme hace 45 años y que todavía soporta las manías, neurosis y rabietas que me ayudan a escribir. Sin ella, mi vida se hubiera disuelto hace tiempo en un torbellino caótico y no hubieran nacido Álvaro, Gonzalo y Morgana ni los seis nietos que nos prolongan y alegran la existencia. Ella hace todo y todo lo hace bien. Resuelve los problemas, administra la economía, pone orden en el caos, mantiene a raya a los periodistas y a los intrusos, defiende mi tiempo, decide las citas y los viajes, hace y deshace las maletas, y es tan generosa que, hasta cuando cree que me riñe, me hace el mejor de los elogios: Mario, para lo único que tú sirves es para escribir"(9). Durante la lectura de este tierno párrafo el escritor conmovió los sentimientos de los asistentes, muchos de los cuales lloraron emocionados. Su esposa reaccionó con sobriedad y elegancia ante este sorpresivo encomio.

\section{Peruanidad}

En su memorable discurso Elogio de la Lectura y la Ficción, MVLl expresó conmocionado: "Al Perú yo lo llevo en las entrañas porque en él nací, crecí, me formé, y viví aquellas experiencias de niñez y juventud que modelaron mi personalidad, fraguaron mi vocación, y porque allí amé, odié, gocé, sufrí y soñé. Lo que en él ocurre me afecta más, me conmueve y exaspera más que lo que sucede en otras partes. No lo he buscado ni me lo he impuesto, simplemente es así" (9).

Continuando con la lectura de su discurso, expresó: "Un compatriota mío, José María Arguedas, llamó al Perú el país de 'todas las sangres'. No creo que haya fórmula que lo 
defina mejor. Eso somos y eso llevamos dentro todos los peruanos, nos guste o no: una suma de tradiciones, razas, creencias y culturas de los cuatro puntos cardinales. A mí me enorgullece sentirme heredero de las culturas prehispánicas que fabricaron los tejidos y mantos de plumas de Nazca y Paracas y los ceramios Mochicas o incas que se exhiben en los mejores museos del mundo, de los constructores de Machu Picchu, el Gran Chimú, Kuelap, Sipán, las huacas de la Bruja y del Sol y la Luna, y de los españoles que, con sus alforjas, espadas y caballos, trajeron al Perú a Grecia, Roma, la tradición jude.cristiana, el renacimiento, Cervantes, Quevedo y Góngora, y la lengua recia de Castilla que los Andes dulcificaron. Y que con España llegara también el África con su reciedumbre, su música y su efervescente imaginación a enriquecer la heterogeneidad peruana. Si escarbamos un poco descubrimos que el Perú, como el Aleph de Borges, es en pequeño formato el mundo entero. ;Qué extraordinario privilegio el de un país que no tiene una identidad porque las tiene todas!" (9).

Y, en su discurso acotó: "El Perú es para mí una Arequipa donde nací pero que nunca viví, una ciudad que mi madre, mis abuelos y mis tíos me enseñaron a reconocer a través de sus recuerdos y añoranzas, porque toda mi tribu familiar, como suelen hacer los arequipeños, se llevó siempre a la Ciudad Blanca con ella en su andariega existencia. Es la Piura del desierto, el algarrobo y el sufrido burrito, al que los piuranos de mi juventud llamaban 'el pie ajeno' -lindo y triste apelativo-, donde descubri que no eran las cigüeñas las que traían los bebes al mundo sino que los fabricaban las parejas, haciendo unas barbaridades que eran pecado mortal. Es el Colegio San Miguel y el Teatro Variedades donde por primera vez ví subir al escenario una obrita escrita por mí. Es la esquina de Diego Ferré y Colón, en el Miraflores limeño -la llamábamos el Barrio Alegre-, donde cambié el pantalón corto por el largo, fumé mi primer cigarrillo, aprendí a bailar, a enamorar y a declararme a las chicas. Es la polvorienta y temblorosa redacción del diario La Crónica donde, a mis dieciséis años, velé mis primeras armas de periodista, oficio que, con la literatura, ha ocupado casi toda mi vida y me ha hecho como los libros, vivir más, conocer mejor el mundo y frecuentar a gente de todas partes $y$ de todos los registros, gente excelente, buena, mala y execrable. Es el Colegio Militar Leoncio Prado, donde aprendí que el Perú no era el pequeño reducto de clase media en el que yo había vivido hasta entonces confinado y protegido, sino un país grande, antiguo, enconado, desigual y sacudido por toda clase de tormentas sociales. Son las células clandestinas de Cahuide en las que con un puñado de sanmarquinos preparábamos la revolución mundial. Y el Perú son mis amigos y amigas del Movimiento Libertad con los que por tres años, entre las bombas, apagones y asesinatos del terrorismo, trabajamos en defensa de la democracia y la cultura de la libertad" (9).

Así mismo, el escritor identifica la esencia del Perú en su "identidad colectiva, la identidad indígena, autóctona, genuina, la de la verdadera peruanidad" (La República, 21 de Diciembre del 2010) . En su obra cumbre Conversación en la Catedral (2), su personaje Santiago Zavalita se preguntaba: ¿En qué momento se había jodido el Perú? Como contraparte, sus seguidores consideran que a partir del 21de agosto de 1987 el Perú comenzó a levantarse el Perú, como consecuencia del multitudinario mitin de la Plaza San Martín, día aquel en que MVLL fue el líder y orador principal contra el intento de nacionalización y estatización de la banca por parte del gobierno de Alan García Pérez. 
En relación a la concesión del Nobel, en conferencia de prensa apuntó que en él "no hay un reconocimiento a la obra de un escritor, sino a la lengua en la que escribe y al país del que procede". Igualmente señaló que el premio "reconoce a la literatura peruana, su tradición y creatividad de los peruanos". El día que el gobierno peruano lo condecoró con la Orden de las Artes y las Letras, en su discurso de orden sentenció, "hagamos que el Perú valga, por fin, un Perú".

Mario Vargas Llosa, José María Arguedas, José Carlos Mariátegui y César Vallejo, son los pensadores que con más profundidad han ahondado el tema de la peruanidad. Arguedas, desde su cosmovisión del mundo andino centrado en el indigenismo autóctono, nacido del inconsciente colectivo del Perú ancestral, siendo sus obras fundamentales, Yawar Fiesta, Los Ríos Profundos, El Zorro de Arriba y el Zorro de Abajo y Todas las Sangres, en las cuales afirma el indigenismo y acrisola el mestizaje. El Amauta José Carlos Mariátegui, con el análisis del feudalismo y explotación inicua de los indios y campesinos del Perú profundo, plasmado principalmente en su obra cumbre 7 Ensayos de Interpretación la Realidad Peruana. César Vallejo, el poeta del dolor humano y poeta universal, que en El Tungsteno y Paco Yunque retrata aspectos del sufrimiento de los explotados del Perú profundo. Y, MVLl, ganador del Premio Nóbel de Literatura 2010, según la Academia Sueca, por su "cartografía de las estructuras del poder y aceradas imágenes de la resistencia, la rebelión y la derrota del individuo", contra todo tipo de autoritarismo, sustentado en las dictaduras militares y el poder colonizador de las potencias mundiales, lo cual se evidencia en su creación literaria, principalmente, Los Jefes, La Ciudad y los Perros, Conversación en la Catedral, La Fiesta del Chivo, La Guerra del Fin del Mundo y El Sueño del Celta (3,4,2,5,6,7). Ellos, han contribuido sustantivamente al conocimiento de la estructura la peruanidad desde el inconsciente indígena y el mestizaje abordado por Arguedas, la conciencia social iluminada por Mariátegui y los valores espirituales defendidos por Vargas Llosa, centrado en la defensa de la libertad en su lucha contra la corrupción y el abuso de poder.

\section{Escritor esencial}

A su retorno al país, MVLl declaró a la prensa que "la publicidad en torno al Nóbel no es la gloria. El verdadero éxito del escritor se vive en la soledad, frente al papel y al escritorio... Es el tipo de satisfacción que más añora y sueña un escritor, lo que venga de fuera es bienvenido y si no viene, no es grave". Y, en su discurso con motivo de la aceptación del Premio Nóbel, citando a Flaubert, MVLl expresó: "Escribir es una manera de vivir".

\section{Primeras creaciones literarias}

En 1952, cuando el adolescente MVLl cursaba el quinto año de secundaria en el Colegio Nacional San Miguel de Piura, logró poner en escena su primera obra teatral escrita el año anterior, el drama, La huída del inca que fue exhibida el 17 de julio de ese año en el Teatro Variedades, con motivo de la Semana de Piura. La representación teatral tuvo tal éxito que a pedido del público la semana siguiente tuvieron que darse dos funciones 
más. Para el efecto, el escritor en cierne tuvo el apoyo decidido del el profesor de Literatura, el "ciego" Carlos Robles Rázuri, el Director del Colegio, Luis Marroquín Andía y del pintor Manuel Aldana Ruiz; además de sus amigos de colegio, entre los que se encontraba el "gordo" Javier Silva Ruete y el elenco de ocho actores novatos. $\mathrm{Al}$ respecto, el escritor refiere: "el teatro fue mi primera devoción literaria", su sueño de entonces fue ser dramaturgo. Su primer libro publicado fue una colección de cuentos titulada Los Jefes (encabezada por el relato del mismo nombre), que obtuvo el premio Leopoldo Alas en 1959 (3).

En 1953, ingresó a la Universidad Nacional Mayor de San Marcos a estudiar Literatura y Derecho. Siendo estudiante sanmarquino publicó sus primeros relatos: "El Abuelo" (1956) y Los Jefes (1957).

"Los Jefes", es un cuento breve en el cual narra un fallido intento de huelga escolar en contra del director del Colegio San Miguel, por haber dispuesto que los exámenes finales se tomarían de manera improvisa y no de acuerdo a un horario preestablecido, para poder evaluar con mayor exactitud los conocimientos de los estudiantes promocionales, entre los cuales se encontraba precisamente el sanmiguelino Mario Vargas Llosa.

\section{Escritor polifacético}

MVLl, es un intelectual polifacético. Ha escrito 18 libros de ficción, entre novelas y cuentos; 18 ensayos; sus memorias (1); obras de teatro, varias adaptaciones cinematográficas de sus novelas, periodista prolífico, crítico literario y conferencista eximio. La Casa Verde es sin duda una de las más representativas y apasionantes novelas de Mario Vargas Llosa. El relato se desarrolla en tiempos distintos, con enfoques diversos de la realidad, a través del recuerdo o la imaginación, y ensamblados con técnicas narrativas complejas que se liberan a través de una desenvoltura narrativa ágil y precisa (8). Conversación en la catedral recrea la opresión de la sociedad peruana bajo la dictadura de Odría a través de diversos ambientes estudiantiles. En la obra se ponen al descubierto, dentro de un complejo entramado de vidas privadas, los mecanismos mentales y morales de los que gobiernan, las costumbres que genera el poder, y las distintas retóricas de las personas que lo ejercen, secundan o envidian (2). La Fiesta del Chivo, novela que se ubica en la República Dominicana y retrata el asesinato del dictador dominicano Rafael Leónidas Trujillo, y sus secuelas, desde dos puntos de vista con una generación de diferencia: durante e inmediatamente después del asesinato en sí, en mayo de 1961, y treinta años más tarde, en 1996. En todo, también hay una amplia reflexión sobre el apogeo de la dictadura, en la década de 1950, y su importancia para la isla y sus habitantes (5).

\section{Política}

Su quehacer político ha sido inagotable en el plano nacional e internacional. Presidente de la Comisión Investigadora del Caso Uchuraccay (1983); lideró protesta popular contra intento de nacionalización y estatización de la banca por parte del gobierno de Alan García Pérez y fundó el Movimiento Libertad (1987). Candidato presidencial por el Frente Democrático (FREDEMO, 1990), perdiendo en segunda vuelta contra el outsider 
Alberto Fujimori, quien tuvo el apoyo del APRA y de las izquierdas. En 1990 calificó como dictadura perfecta al sistema político mexicano, dominado por el PRI durante más de seis décadas. Adquiere la nacionalidad española, sin renunciar su nacionalidad peruana ante el riesgo de convertirse en un apátrida por la amenaza del gobierno de Fujimori de quitarle la nacionalidad peruana (1993). Presidente de la Comisión del Lugar de la Memoria del Perú, dedicado a las víctimas del conflicto armado interno, al cual renunció irrevocablemente, por su desacuerdo con la amnistía disimulada que pretendía dar Alan García Pérez a los asesinos de La Cantuta y Barrios Altos, lo cual obligó al Presidente de la República a retroceder en ese propósito de consagrar la impunidad. Ha manifestado su repudio a las dictaduras de diferentes países.

\section{Represalia de la dictadura}

El gobierno dictatorial de Fujimori intentó privarlo de la nacionalidad peruana, lo cual indujo a MVLl a solicitar la nacionalidad española, la misma que le fue concedida. Desde entonces el escritor posee la doble nacionalidad peruano española, primando en él su sentimiento de peruanidad, lo cual se plasma en la cuasi totalidad de su monumental obra.

\section{Demócrata por antonomasia}

A su retorno al país, procedente de Madrid (13/12/2010), se autorretrató una vez más como demócrata consumado al manifestar a la prensa que "Si la hija del dictador que está condenado a la cárcel por criminal y por ladrón, tiene la posibilidad de ser presidenta del Perú, voy a ser uno de los peruanos que saldrán a tratar de impedirlo por todos los medios legales posibles. Sería una verdadera catástrofe para el país". Seguidamente, instó a la clase política a remar juntos en aras del progreso del Perú. Declaró que "el país está progresando en los últimos diez años, no sólo por el crecimiento económico, sino porque aparece como una democracia que va a la modernidad. Falta mucho por hacer y es importante que quienes hacen politica en este contexto, muevan el país hacia adelante y no lo hagan retroceder".

\section{Defensor de la libertad}

El laureado escritor ha consagrado su vida en favor de la lucha por la libertad, los derechos civiles y los derechos humanos. Su obra toda es expresión de la rebeldía y resistencia del individuo ante la opresión de la autoridad en busca de su libertad, bien supremo del ser humano. En sus ficciones, desde Los Jefes hasta El Sueño del Celta, su leitmotiv es la lucha indeclinable por la justicia y la libertad, siempre arrancada a los opresores más protervos.

\section{Premios, Condecoraciones y reconocimientos académicos}

MVLl ha ganado todos los premios posibles en el ámbito nacional e internacional; a saber, Segundo Premio del III Concurso de Teatro Escolar y Radioteatro Infantil del Ministerio 
de Educación Pública, drama La huida del Inca (1952), Premio de la Revue Francaise, El Desafio (1957), Premio Leopoldo Alas (1959) por su primer libro, serie de cuentos, Los Jefes. Siguieron, el Premio Biblioteca Breve de Novela (1963) por La Ciudad y los Perros; Premio Rómulo Gallegos (1967) por La Casa Verde; Premio Príncipe de Asturias de las Letras (1986); Premio Planeta (1993) por Lituma en los Andes; Premio Cervantes (1994) y el Premio Nóbel de Literatura (1.1.2010), entre los principales.

Así mismo, universidades del mayor prestigio internacional y nacional le han concedido el grado de Doctor Honoris Causa, entre ellas, Harvard, Oxford, la Sorbona, Yale, Autónoma de México y Nacional Mayor de San Marcos, su alma máter.

De modo que MVLl es el peruano más condecorado en el ámbito nacional e internacional. En el Perú, antes y después de recibir el Premio Nóbel de manos del rey Carlos XVI Gustavo de Suecia en Estocolmo, una legión de instituciones políticas, académicas, culturales, empresariales y sociales, se engalanaron premiándolo con sus condecoraciones de mayor rango. La presidencia de la República, el Congreso Nacional, el Poder Judicial y universidades, le han concedido sendos reconocimientos, doctorados honoris causa y profesor emérito, entre otras distinciones. El gobierno le concedió la máxima distinción que otorga el Estado peruano, la Orden del Sol del Perú en el Grado de Gran Cruz con Diamantes. También, es miembro de la Academia Peruana de la Lengua y de la Real Academia Española.

\section{Peruano universal}

La Oficina de las Naciones Unidas para la Educación, la Ciencia y la Cultura, UNESCO, mediante su representante en Lima, Nilda Anglarill, consideró que MVLl, "es el personaje más universal que ha concebido este país. Sus obras se leen en todos los rincones del mundo y muchos conocen a Perú a través de éstas" (La República, 15 de Diciembre del 2010). Sus obras La Fiesta del Chivo, La Guerra del Fin del Mundo y El Sueño del Celta muestran la universalidad en la literatura del genial escritor $(5,6,7)$.

\section{Discurso de aceptación del Nóbel}

El Elogio de la Lectura y la Ficción, es un discurso erudito. Una pieza retórica pulcra en la cual se plasma la maestría literaria vargallosiana. Una síntesis coherente de su estela biográfica, personal, familiar literaria e intelectual; sus raíces telúricas, las fuentes de inspiración de su prolífica ficción y su cosmovisión del mundo posmoderno, desde su ideología del liberalismo (9).

\section{Sus repulsas}

Varios escritores europeos elogiándolo, lo definen como "el más europeo de los escritores latinoamericanos". Coherente con su etnocentrismo occidental, MVLl abomina del indigenismo, el nacionalismo y los integrismos religiosos. Desde esta perspectiva afirma que "si queremos alcanzar el desarrollo y elegir la civilización y la moralidad, tenemos que combatir resueltamente esos brotes de colectivismo. Creo que en el movimiento 
indígena hay un elemento profundamente perturbador que apela a los bajos instintos, a los peores instintos del individuo como la desconfianza hacia el otro, al que es distinto. Entonces se encierran en sí mismos". Sin embargo, el Nóbel europeo José Saramago, retrucó esta posición vargallosiana, así: "Decir que el movimiento indígena es un peligro para la democracia, me parece algo increíble. Cómo de una cabeza inteligente puede salir una afirmación tan monstruosa como esa".

En efecto, para quienes propugnan el etnocentrismo occidental, lo propio es lo "lo humano" y lo de los otros, "lo inhumano". En su escala axiológica los etnocentristas asumen que los indígenas son desconfiados y cerrados sobre sí mismos en la misma medida en que los occidentales son confiados y abiertos. Por eso MVLl, piensa que el indigenismo, el nacionalismo y los integrismos religiosos son parte del mal que se debe combatir (La República, 21 de Diciembre del 2010). Algo así como la supuesta razón y aparente legitimidad de las Cruzadas medievales contra los musulmanes de Medio Oriente, por la recuperación de Jerusalén en nombre del cristianismo.

\section{Posición controversial}

Como miembro de la Comisión Latinoamericana sobre Drogas y Democracia, presidida por Fernando Henrique Cardoso (e.presidente de Brasil) e integrada por César Gaviria (e.presidente de Colombia) y Ernesto de Zedillo (e.presidente de México), Paulo Coelho, escritor y Diego García Sayán, jurista, entre 18 personalidades de la región, MVLl propugna la discriminalización y despenalización del consumo de drogas con argumentos políticos, ideológicos y crematísticos centrados en el mercado; ignorando la otra cara de la medalla del problemas, el grave aspecto clínico de las adicciones, la tragedia griega familiar y la disrupción del tejido social.

\section{Colofón}

MVLl es un ser humano de sensibilidad profunda con una portentosa capacidad de ficción, en busca de la libertad, la misma que arranca de la opresión de los dictadores y tiranos de todo jaez a los que desnuda con su pluma implacable, irritándolos. Sus obras son eso, expresión de amor a la libertad y capacidad creativa inagotable, dotada de pasión y del más elevado rigor, disciplina férrea y genialidad creativa. Vive en dos mundos asimétricos, el de la pequeña realidad y el de la infinita ficción, su refugio sacralizado. Comprometido con los principios y las causas en las que él cree. Conocido como una persona, bondadosa, generosa, exigente, obsesiva, meticulosa, posesiva, adicta al trabajo de escriba. Caballero, padre, esposo, abuelo y patriarca paradigmático.

Su rechazo al autoritarismo se forjó en su niñez temprana, la cual estuvo impregnada de miedo y rencor contra una figura paterna tiránica, sin contrapeso materno capaz de protegerlo durante los episodios de violencia explosiva del padre. Entonces, resistió refugiándose en la ficción, tornándose adicto a la lectura, la escritura y la fabulación. De una infancia y niñez temprana feliz en su familia materna; de manera abrupta pasó a una niñez tardía y adolescencia tormentosa, debido a los brutales maltratos paternos sufridos por él y su madre durante tres años. Entonces, afloró su resiliencia, resistió e 
imaginariamente se rebeló contra toda forma de poder abusivo a través de la creación literaria, su panacea. De esta manera proactiva sublimó sus miedos y odios infantiles contra su ogro paterno en beneficio de la sociedad, contribuyendo poderosamente a su enriquecimiento humanista.

Su pensamiento ideológico pasó del vehemente socialismo juvenil al militante liberalismo de su madurez y longevidad. Nacido para ser intelectual polifacético triunfador. No tuvo éxito en política, quehacer que le deparó incomprensiones, sinsabores y el fracaso de su candidatura presidencial. Su perseverancia lo condujo a persistir en el logro de sus sueños, sin arriar banderas nunca. Los frutos de este peruano universal están a la vista, para orgullo de sus compatriotas. Su vida es un paradigma internacional; un humanista ecuménico (9).

\section{REFERENCIAS BIBLIOGRÁFICAS}

1. Vargas Llosa, Mario (2005). El pez en el agua. Santillana.

2. Vargas Llosa, Mario (1969). Conversación en la catedral. Editorial PEISA.

3. Vargas Llosa, Mario (1980). Los jefes. Editorial Seix Barral, S.A.

4. Vargas Llosa, Mario (1986). La ciudad y los perros. Editorial Seix Barral, S.A.

5. Vargas Llosa, Mario (2000). La fiesta del chivo. Editorial Alfaguara.

6. Vargas Llosa, Mario (2003). La guerra del fin del mundo. Santillana.

7. Vargas Llosa, Mario (2010). El sueño del celta. Editorial Alfaguara.

8. Vargas Llosa, Mario (1966). La casa verde. Editorial Seix Barral S.A.

9. Fundación Nóbel (2010). Mario Vargas Llosa: Elogio de la lectura y la ficción (folleto). Discurso Nóbel, Estocolmo 7 de diciembre de 2010. 